\title{
Maturation Schedules of Walleye Populations in the Great Lakes Region: Comparison of Maturation Indices and Evaluation of Sampling-Induced Biases
}

\author{
HuI-Yu Wang \\ Cooperative Institute for Limnology and Ecosystems Research, School of Natural Resources and \\ Environment, University of Michigan, National Oceanic and Atmospheric Administration, \\ Great Lakes Environmental Research Laboratory, 2205 Commonwealth Boulevard, Ann Arbor, \\ Michigan 48105, USA, and Department of Natural Resources Conservation, \\ University of Massachusetts Amherst, 160 Holdsworth Way, Amherst, Massachusetts 01003, USA
}

\section{H. ANDREw CoOK}

Ontario Ministry of Natural Resources, Lake Erie Management Unit, Rural Route 2, 320 Milo Road, Wheatley, Ontario NOP 2P0, Canada

\section{DonAld W. EINHOUSE}

New York State Department of Environmental Conservation, Lake Erie Fisheries Research Unit, 178 Point Drive North, Dunkirk, New York 14048, USA

DAVID G. FIELDER

Michigan Department of Natural Resources, Alpena Fisheries Research Station, 160 East Fletcher, Alpena, Michigan 49707, USA

\section{Kevin A. KaYLe}

Ohio Department of Natural Resources, Division of Wildlife, Fairport Fisheries Research Station, 1190 High Street, Fairport Harbor, Ohio 44077, USA

\section{LARS G. RUDSTAM}

Department of Natural Resources, Cornell University Biological Field Station, 900 Shackelton Point Road, Bridgeport, New York 13030, USA

TOMAS O. HöÖK*

Cooperative Institute for Limnology and Ecosystems Research, School of Natural Resources and Environment, University of Michigan, National Oceanic and Atmospheric Administration, Great Lakes Environmental Research Laboratory, 2205 Commonwealth Boulevard, Ann Arbor, Michigan 48105, USA, and Department of Forestry and Natural Resources, Purdue University, 195 Marsteller Street, West Lafayette, Indiana 47907, USA

\begin{abstract}
Maturation schedules, key determinants of fish stocks' harvest potential and population dynamics, are influenced by both plastic and adaptive processes. Various indices are used to describe maturation schedules, and these have differential advantages for discriminating between plastic and adaptive processes. However, potential sampling-related biases associated with different maturation indices have not been fully evaluated. We analyzed three maturation indices for walleyes Sander vitreus in Lake Erie; Saginaw Bay, Lake Huron; and Oneida Lake, New York: age and length at 50\% maturity, midpoint of age-specific maturity ogives (age-specific length at which probability of maturity $=0.50$ ), and midpoints of probabilistic maturation reaction norms (PMRNs; age-specific length at which probability of maturing in the following year $=0.50$ ). We then compared estimated maturation indices to evaluate sensitivity of different maturation indices to sampling-induced biases and to assess the relative importance of plastic versus adaptive processes in structuring interstock and temporal variation in maturation schedules. Our findings suggest that although small changes in sampling month, gear, and agency-related effects can bias estimates of age and length at $50 \%$ maturity and midpoints of maturity ogives, PMRN estimates appear to be robust to these biases. Furthermore, PMRN estimates are suggestive of potential adaptive variation in maturation schedules among walleye stocks and over time. For instance, Oneida Lake walleyes (which had relatively slow growth and low mortality rates)
\end{abstract}

\footnotetext{
* Corresponding author: thook@purdue.edu
}

Received July 2, 2008; accepted May 15, 2009

Published online October 12, 2009 
matured at a smaller size for a given age (smaller midpoints of PMRNs) than the other stocks. Temporally, walleyes in the western basin of Lake Erie matured at a larger size in recent years, as evidenced by increasing midpoints of PMRNs (1978-1989 versus 1990-2006 for Ohio Department of Natural Resources data and 1990-1996 versus 1997-2006 for Ontario Ministry of Natural Resources data). Our study highlights the necessity of monitoring maturation schedules via multiple maturation indices and the need to account for sampling-induced biases when comparing maturation schedules.

Maturation schedules (i.e., typically age and size at maturity) are influenced by genetic selection and environmental processes (including anthropogenic activities) that selectively impact growth and mortality (Law 2000; Dieckmann and Heino 2007). Discrimination between adaptive and plastic variation in maturation schedules can be insightful because an adaptive maturation schedule is intrinsic to a stock and may be difficult to reverse (Olsen et al. 2005; Conover et al. 2009), whereas plastically determined maturation schedules may readily respond to management actions. Moreover, understanding variation in maturation schedules is fundamental to effective fishery resource management. Maturation schedules influence reproductive potential, directly affecting fitness (i.e., number of offspring that survive to reproduce) at both individual and population levels (Stearns 1992), and thereby determines a fish stock's sustainable harvest potential (Trippel 1995). Thus, intraspecific comparisons of maturation schedules among stocks may allow for gauging of the current status and relative sustainability of multiple fish stocks. In fact, such interstock variation in maturation schedules is well documented for lake whitefish Coregonus clupeaformis (Taylor et al. 1992) and lake trout Salvelinus namaycush (McDermid et al. 2007).

It is, however, difficult to distinguish between plastic and adaptive changes in maturation schedules because these changes may occur simultaneously and have different magnitudes and directions (Law 2000). Although most previous studies investigating spatial and temporal variation in maturation schedules have relied on estimates of age $\left(A_{50}\right)$ and length $\left(L_{50}\right)$ at $50 \%$ maturity, several authors suggest that these estimates are sensitive to biases related to variation in growth and mortality rates (Heino et al. 2002; Dunlop et al. 2005). Thus, these indices are not suitable for distinguishing between plastic and selection-induced changes in maturation schedules. More recently, several studies have estimated midpoints of probabilistic maturation reaction norms (PMRNs) - the length at which probability of maturing $=0.50$ for given ages-to characterize maturation schedules while accounting for the effects of growth and mortality rates (Heino et al. 2002; Dunlop et al. 2005; Dieckmann and Heino 2007). Such studies have demonstrated both within-stock temporal variation and among-stock spatial variation in adap- tively determined maturation schedules (e.g., sizeselective fisheries may lead to decreased age and size at maturity; Grift et al. 2003; Olsen et al. 2004, 2005).

Estimates of maturation indices also may be influenced by sampling effects that may impart biases. Sampling with different gears or during different times of year may affect the size distribution of fish captured and may impact how individual maturity status is evaluated. It is well understood that $A_{50}$ and $L_{50}$ estimates are affected by such sampling-related biases. In contrast, past studies suggest that as PMRNs account for variation in growth and mortality, this index should be relatively robust to the specific size-distributions analyzed and, thus, should be less affected by sampling-related estimation biases (Dieckmann and Heino 2007). Further, Olsen et al. (2005) suggested that PMRN estimates are rather insensitive to variation in sampling month. However, the differential effects of sampling-related biases (e.g., collection gear, time of assessment) on these maturation indices have not been fully evaluated.

We compared multiple maturation indices of walleyes Sander vitreus from throughout the Laurentian Great Lakes region, including the western, central, and eastern basins of Lake Erie; Saginaw Bay of Lake Huron; and Oneida Lake, New York. These ecosystems have all historically supported important walleye fisheries (Forney 1977; Schneider and Leach 1977; Fielder 2002) with variable harvest and management practices. Presently, walleyes are harvested by both commercial and sport fisheries in Lake Erie (Knight 1997) but solely by anglers in Saginaw Bay and Oneida Lake (VanDeValk et al. 2002; Fielder and Thomas 2006). Previous research suggests that walleyes in these lakes are genetically distinct (Billington and Hebert 1988; Billington et al. 1992; McParland et al. 1999), but the genetic distinctiveness among Lake Erie stocks is somewhat equivocal (Merker and Woodruff 1996; Strange and Stepien 2007). It is clear that these stocks display variable maturation schedules, growth, and mortality rates. Walleyes in Oneida Lake have relatively low growth and mortality rates and mature at old ages (Forney 1977; He et al. 2005) compared with Lake Erie walleyes, which experience much higher mortality rates and display intermediate growth rates and a relatively early onset of maturation (Colby and Nepszy 1981; Wang 2003). Growth rates of walleyes in 
Saginaw Bay have historically been high but have declined in recent years (Fielder and Thomas 2006).

We estimated (1) $A_{50}$ and $L_{50}$, (2) the age-specific length at which the probability of a fish being mature is 0.50 , hereafter referred to as the midpoint of the agespecific maturity ogive $\left(L_{50, a}\right.$, where $a$ indexes for age; ogives are probabilities of being mature for given ages; Barot et al. 2004a, 2004b), and (3) the age-specific length at which the probability of a fish maturing in the following year is 0.50 , hereafter referred to as the midpoint of the PMRN $\left(L \mathrm{p}_{50, a}\right)$. Our objectives were to evaluate biases related to estimating maturation indices (i.e., potential confounding factors such as different sampling months, gear types, and agencies) and to identify whether the walleye stocks studied display intrinsically different maturation schedules across space and over time. Month of sampling may affect the ability to accurately identify maturation state and observed length distributions. That is, since walleyes grow relatively fast in fall when water temperatures are bioenergetically favorable (Kitchell et al. 1977; Kershner et al. 1999), size differences across months may be pronounced. Moreover, different sampling gear may also bias observed age and length distributions. Furthermore, discrepancies in estimates from various agencies may arise from differences in sampling procedures, including sampling different locations and agency-specific biases in assessing age and maturation state. Comparison of these three maturation indices provides complementary information for distinguishing potential plastic and adaptive variation in maturation schedules (e.g., plastic variation in maturation schedules may induce changes in $A_{50}$ and $L_{50}$ but not in PMRNs; Wang et al. 2008), and it is thus useful to elucidate potential sampling-related biases.

\section{Methods}

\section{Data}

We analyzed fisheries-independent survey data (including total length, sex, age, and maturation state) of individual walleyes collected by five assessment programs in three lakes (Figure 1; Table 1): Ohio Department of Natural Resources (ODNR; western and central basins of Lake Erie), Ontario Ministry of Natural Resources (OMNR; all three basins of Lake Erie), New York State Department of Environmental Conservation (NYSDEC; eastern basin of Lake Erie), Michigan Department of Natural Resources (MDNR; Saginaw Bay of Lake Huron), and Cornell University (CU; Oneida Lake). Although all five programs conducted surveys during spring and fall, only fall open-lake surveys (late August to November) target both mature fish (i.e., those that will spawn during the next year) and immature fish (i.e., those that will not spawn during the next year). Information relating to both maturity states is necessary to quantify population-level maturation indices. All programs internally examined sex and maturation state to assess whether a fish would or would not spawn in the following spring, but aging methods varied among programs. Otoliths were used by ODNR, OMNR, and NYSDEC; scales were used by CU, MDNR, OMNR, and NYSDEC; and dorsal spines were used by MDNR, ODNR, and NYSDEC. Aging biases should be pronounced only for old, slow-growing fish (Schneider 2001; H.-Y. Wang, unpublished data: different aging methods were generally consistent for fish of age $\leq 7$ ). Although sex and maturation state of most walleyes collected in fall can be identified by inspecting gonads (Forney 1965; Goede and Barton 1990; Henderson et al. 1996), there may be relatively high uncertainty in maturity identification during early fall (A. Cook, unpublished data). Note that all ages reported herein are fall ages, and actual spawning by mature individuals would have taken place when the fish were 1 year older.

The sampling protocols used by each assessment program were generally consistent over time but varied among agencies. The ODNR surveys (SeptemberOctober of 1978-2006) in the western and central basins were located at seven fixed sites, and each year approximately 50 additional sites were selected using a stratified random method (ODW 2006; Figure 1). At all sites, suspended multifilament gill nets (13 panels, each $30.5 \times 1.8 \mathrm{~m}$; graded stretched mesh sizes from 51 to $127 \mathrm{~mm}$ in 6-mm increments; panels randomly ordered) were set overnight. In addition, at the seven fixed sites, suspended and bottom monofilament gill nets $(12$ panels total, each $15.2 \times 1.8 \mathrm{~m}$; 6 panels with stretched mesh sizes from 32 to $76 \mathrm{~mm}$ in 6-mm increments; plus 6 panels with stretched mesh sizes from 76 to $127 \mathrm{~mm}$ in 12-mm increments; panels randomly ordered) were also used (ODW 2006). Almost all walleyes captured by multifilament gill nets were collected during October (96\% in the western basin and over $99 \%$ in the central basin); similarly, all walleyes caught by monofilament gill nets during 1996-2006 were captured during October. However, monofilament gill-net catches during 1992-1995 included samples collected in both September (western basin $N=1,526$; central basin $N=633$ ) and October (western basin $N=1,230$; central basin $N=1,043$ ).

The OMNR (1989-2006) used monofilament suspended and bottom gill nets at sites randomly selected within the three Lake Erie basins (Figure 1). Each gillnet set was composed of three small panels (each 15.2 $\times 1.8 \mathrm{~m}$; mesh sizes $=32,38$, and $44 \mathrm{~mm}$ ) plus 9 large panels $(30.5 \times 1.8 \mathrm{~m}$; mesh sizes $=51,57,64,70,76$, $89,102,114$, and $127 \mathrm{~mm}$ ) or 11 large panels (i.e., 


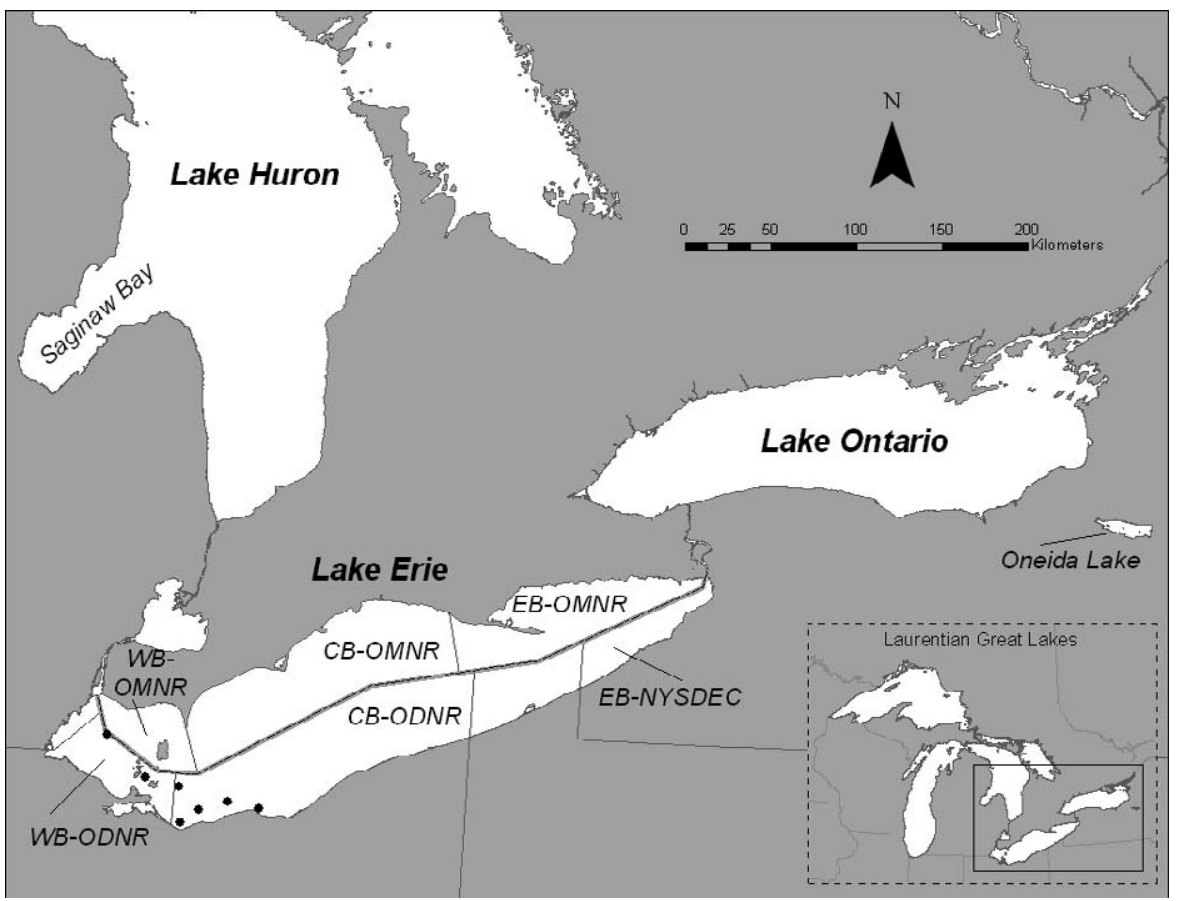

FIGURE 1.-Map of study area, including the western basin (WB), central basin (CB), and eastern basin (EB) of Lake Erie; Saginaw Bay, Lake Huron; and Oneida Lake, New York. The three basins were surveyed by multiple agencies (see abbreviations listed in Table 1): WB and CB surveys involved OMNR and ODNR, and EB surveys involved OMNR and NYSDEC. Although ODNR conducted surveys at seven fixed sites (black dots) and additional randomly selected sites, all other Lake Erie agencies used a stratified random sampling procedure.

mesh sizes of 140 and $152 \mathrm{~mm}$ were added for 1993 and later years); panels were randomly ordered. During 1989-1990 and 1999-2001, additional gangs of nets were set in the eastern basin. Each year, the surveys were conducted first in the eastern basin from late August (24\% of samples) to early September (73\%), when the thermocline was present. Sampling then continued in the western basin from September $(86 \%)$ to October (14\%) and the central basin from late September $(15 \%)$ to October, following fall turnover (85\%; A. Cook, unpublished data).

The 1981-2006 coverage of NYSDEC surveys was generally consistent spatially and over time (September-October), but sampling methods changed in 1993. From 1981 to 1992, NYSDEC conducted surveys in the eastern basin at 24 fixed nearshore stations (depths $=5.5-11.0 \mathrm{~m})$ via bottom multifilament gill nets $(8$ panels, each $15.2 \times 1.8 \mathrm{~m}$; graded stretched mesh sizes of $38-127 \mathrm{~mm}$ in $13-\mathrm{mm}$ increments). From 1993 to 2006, NYSDEC used sampling procedures similar to ODNR and OMNR. The post-1993 sites were selected using a stratified random approach and were sampled with monofilament gill nets (14 panels, each $15.2 \times 1.8$ $\mathrm{m}$; stretched mesh sizes of $32-152 \mathrm{~mm}$ in $9-\mathrm{mm}$ increments; panels randomly ordered). Both suspended and bottom gill nets were set during 1993-1995; only bottom gill nets were set during 1996-2006. Moreover, since 2005, deployment of the largest-mesh panel (152$\mathrm{mm}$ mesh) was ceased so as to minimize likelihood of net damage (Einhouse et al. 2005).

Since 1989, MDNR surveys in Saginaw Bay have been conducted annually in September at nine fixed sites throughout the bay (Fielder and Thomas 2006). The agency has employed two overnight sets of bottom multifilament gill nets per site (each net with 11 panels, $30.5 \times 2.0 \mathrm{~m}$; stretched mesh sizes $=38,51,57,64,70$, $76,83,89,102,114$, and $127 \mathrm{~mm}$ ).

Lastly, CU surveys (October-November 1961-2005) were conducted using a variety of methods, including bottom trawling (14.0- and 5.5-m-opening bottom trawls; $94 \%$ of samples), trap nets (3\% of samples), and nighttime electrofishing surveys (3\% of samples). Trawling surveys targeted sites throughout Oneida Lake (for more details, see Rudstam et al. 2004).

\section{Analysis}

To compare variation in maturation schedules among walleye stocks, we estimated three types of 
TABLE 1.- Sources, spatial and temporal extent, gear types, and sample sizes $(N)$ of data used to analyze maturation indices of walleyes from the eastern (EB), central (CB), and western (WB) basins of Lake Erie; Saginaw Bay, Lake Huron; and Oneida Lake, New York, as sampled by the Ohio Department of Natural Resources (ODNR), Ontario Ministry of Natural Resources (OMNR), New York State Department of Environmental Conservation (NYSDEC), Michigan Department of Natural Resources (MDNR), and Cornell University (CU) via multifilament (multi) and monofilament (mono) gill net $(\mathrm{GN})$, trawl (TW), trap net (TP), and electrofishing $(\mathrm{EF})$.

\begin{tabular}{lcccr}
\hline \multicolumn{1}{c}{ Area } & Year & Month & Gear & Walleye $N$ \\
\hline \multicolumn{4}{c}{ ODNR, Lake Erie } \\
WB & $1978-2006$ & Sep-Oct & Multi GN & 32,678 \\
WB & $1992-2006$ & Sep-Oct & Mono GN & 4,039 \\
CB & $1981-2006$ & Sep-Oct & Multi GN & 14,824 \\
CB & $1990-2006$ & Sep-Oct & Mono GN & 2,648 \\
\multicolumn{5}{c}{ OMNR, Lake Erie } \\
WB & $1990-2006$ & Sep-Oct & Mono GN & 17,433 \\
CB & $1989-2006$ & Sep-Oct & Mono GN & 13,053 \\
EB & $1989-2006$ & Aug-Oct & Mono GN & 2,386 \\
\multicolumn{5}{c}{ NYSDEC, Lake Erie } \\
EB & $1981-2006$ & Sep-Oct & Mono GN \\
\multicolumn{4}{c}{ MDNR, Lake Huron } \\
Saginaw Bay & $1989-2006$ & Sep & Multi GN \\
\multicolumn{4}{c}{ CU, Oneida Lake } \\
All of lake & $1961-2005$ & Oct-Nov & TW, TP, EF & 3,318 \\
\hline
\end{tabular}

sex-specific maturation metrics (because walleyes display sexually dimorphic growth and maturity patterns; Henderson and Morgan 2002) with bootstrapped $95 \%$ confidence intervals (CIs): (1) $A_{50}$ and $L_{50}$, (2) $L_{50, a}$, and (3) $L \mathrm{p}_{50, a}$. Analytic procedures for these metrics are described in Barot et al. (2004a, 2004b) and Wang et al. (2008). Estimation procedures were similar for all metrics but involved differential grouping of data. For example, all three metrics involved fitting a logistic regression (e.g., using length or age as a predictor with binary maturation state $[0=$ immature; $1=$ mature] as the response variable). This was then used to estimate the length (or age in the case of $A_{50}$ ) at which the probability of maturity was 0.50 . We estimated $A_{50}$ and $L_{50}$ by pooling all samples of a sex within a stock, whereas $L_{50, a}$ was estimated by grouping only samples of a given age-sex-stock group. Following the fitting of a logistic regression for age-sex-stock-specific maturity ogives, we estimated $L \mathrm{p}_{50, a}$ in two steps. First, we calculated the agesex-stock-specific probability of maturing as the ratio of (1) the probability of an immature individual at age $a$ -1 being mature at age $a$ and (2) the probability of being immature at age $a-1$ (estimated based on the average growth increment from age $a-1$ to age $a$ ). This ratio function assumes that growth and survival are the same for immature and mature individuals; however, estimation of $L \mathrm{p}_{50, a}$ is robust when this assumption is violated (Barot et al. 2004a, 2004b). Second, we fit a logistic regression (with length at age $a$ as a predictor and probability of maturing as the response variable) to estimate $L \mathrm{p}_{50, a}$ (Barot et al. 2004a, 2004b; Wang et al. 2008). Note that estimation of $L \mathrm{p}_{50, a}$ typically requires relatively large sample sizes of around 100 individuals each for age $a$ and age $a-1$ (Barot et al. 2004a, 2004b). Thus, we were not able to estimate $L \mathrm{p}_{50, a}$ by year; to facilitate comparisons of maturation indices, we grouped data across time (see below). Moreover, we only reported indices estimated via valid logistic regression models based on both a deviance-based test (at $\alpha=0.05)$ and visual inspection of fit. Statistical inferences were based on comparison of the $95 \%$ CIs (i.e., two estimates varied significantly if their $95 \%$ CIs did not overlap).

Exploration of sampling biases.-Using Lake Erie survey data, we performed a series of analyses to explore how differences in sampling methods (e.g., month of sampling, gear type, and agency effects) may impact estimates of maturation metrics. Our data only permitted us to examine sensitivity of maturation indices within relatively similar sampling times (September versus October) and gears (multifilament versus monofilament gill nets), making our evaluation of sensitivity relatively conservative.

To evaluate effects of these factors, we selected comparable subsets of data and evaluated changes of a given maturation index (the estimates and 95\% CI) based on each subset. Further, for each data set, our evaluation was limited in the estimable sex-specific, age-specific, and location-specific estimates. We used ODNR monofilament gill-net data (1992-1995) from the western and central basins to evaluate sensitivity of maturation indices to month of sampling: September and October. With respect to gear (multifilament versus monofilament gill nets), we analyzed ODNR data collected in October of 1992-2006 in the western and central basins. Although we pooled data across multiple years for this analysis, the sample sizes over time were roughly consistent across gears and, thus, confounding effects by annual variation in sample size were minimal. Finally, to consider agency effects, we analyzed monofilament gill-net data collected in September 1993-1995 in the western basin (ODNR versus OMNR), October 1989-2006 in the central basin (ODNR versus OMNR), and September 19892006 in the eastern basin (OMNR versus NYSDEC). Tagging studies suggest that during fall, walleyes are recaptured throughout each of the basins independent of tagging locations (Wang et al. 2007), and recent genetic analyses indicate that genetic variation of 
TABLE 2.-Estimated age at $50 \%$ maturity $\left(A_{50}\right.$; years) and length at $50 \%$ maturity $\left(L_{50} ; \mathrm{mm} ; 95 \%\right.$ confidence intervals in parentheses) for male and female walleyes $(N=$ number examined) from the central and western basins of Lake Erie by month of sampling (September versus October), based on Ohio Department of Natural Resources monofilament gill-net data (1992-1995).

\begin{tabular}{|c|c|c|c|c|c|c|}
\hline \multirow[b]{2}{*}{ Month } & \multicolumn{3}{|c|}{ Male } & \multicolumn{3}{|c|}{ Female } \\
\hline & $N$ & $A_{50}$ & $L_{50}$ & $N$ & $A_{50}$ & $L_{50}$ \\
\hline \multicolumn{7}{|c|}{ Western basin } \\
\hline Sep & 787 & $1.4(1.3-1.4)$ & $333(329-338)$ & 703 & $2.8(2.6-3.0)$ & $447(437-460)$ \\
\hline Oct & 559 & $1.1(1.0-1.2)$ & $331(326-337)$ & 349 & $2.6(2.5-2.8)$ & $457(447-467)$ \\
\hline \multicolumn{7}{|c|}{ Central basin } \\
\hline Sep & 291 & $1.4(1.1-1.6)$ & $341(332-349)$ & 288 & $2.4(2.1-2.7)$ & $441(425-455)$ \\
\hline Oct & 498 & $1.2(1.1-1.2)$ & $339(332-346)$ & 460 & $2.6(2.4-2.7)$ & $462(454-470)$ \\
\hline
\end{tabular}

walleyes within a basin is limited (Strange and Stepien 2007). Thus, we would expect that fall collections by different agencies within a basin would target similar walleyes and that resulting differences in maturation indices would primarily result from agency-specific methodological differences (e.g., differential biases for identification of maturity state) and not from collection of different walleye substocks.

Spatial and temporal variation.-We aimed to evaluate spatial and temporal variation in walleye maturation schedules by estimating and comparing maturation indices based on different spatial or temporal subsets of data. In so doing, we relied on our sampling biases evaluation to guide how we assimilated data. To consider spatial variation, we estimated all indices based on data combined from all gear types collected during September and October 1989-2006, but based on the evaluation of sensitivity of maturation indices to potential biasing factors, we did not combine data across assessment agencies. Results of the above analyses suggested that $A_{50}$ and $L_{50}$ estimates are probably sensitive to size biases introduced by combining samples collected in different months and gears. However, by accounting for growth and mortality variation, PMRN estimates should be less sensitive to such biasing factors. To explore temporal variation of maturation indices, we aggregated fish by estimated year-classes into two approximately equal groups. Although data of either temporal group might be disproportionately represented by certain strong year-classes, there were insufficient data to estimate separate maturation indices for each annual cohort.

\section{Results}

Sensitivity of Maturation Indices to Sampling Month, Gear, and Agency

Estimates of $A_{50}$ and $L_{50}$ appear to be sensitive to sampling month, gear, and agency (Tables 2-4). Although female $A_{50}$ and $L_{50}$ did not vary by sampling month or gear, one $L_{50}$ estimate (central basin) and multiple $A_{50}$ estimates for males varied significantly by month and gear (Tables 2, 3). Furthermore, all estimates of $A_{50}$ and $L_{50}$ for both sexes varied significantly across assessment programs, even when controlling for gear and month of capture (Table 4).

In contrast, estimates of sex-age-specific $L_{50, a}$ and $L \mathrm{p}_{50, a}$ appeared to be relatively robust to samplingrelated biases. For example, $L_{50, a}$ and $L \mathrm{p}_{50, a}$ for age-3 females in the western basin did not vary significantly

TABLE 3.-Estimated age at $50 \%$ maturity $\left(A_{50} ;\right.$ years $)$ and length at $50 \%$ maturity $\left(L_{50} ; \mathrm{mm} ; 95 \%\right.$ confidence intervals in parentheses) for male and female walleyes ( $N=$ number examined) collected from the central and western basins of Lake Erie by multifilament versus monofilament gill-net gear, based on Ohio Department of Natural Resources surveys conducted during October of 1992-2006.

\begin{tabular}{|c|c|c|c|c|c|c|}
\hline \multirow[b]{2}{*}{ Gear } & \multicolumn{3}{|c|}{ Male } & \multicolumn{3}{|c|}{ Female } \\
\hline & $N$ & $A_{50}$ & $L_{50}$ & $N$ & $A_{50}$ & $L_{50}$ \\
\hline \multicolumn{7}{|c|}{ Western basin } \\
\hline Multi GN & 7,614 & $1.0(0.9-1.0)$ & $326(323-328)$ & 4,666 & $2.5(2.5-2.5)$ & $464(462-466)$ \\
\hline Mono GN & 1,244 & $1.0(1.0-1.1)$ & $327(324-331)$ & 889 & $2.5(2.4-2.6)$ & $458(452-463)$ \\
\hline \multicolumn{7}{|c|}{ Central basin } \\
\hline Multi GN & 4,756 & $0.9(0.8-0.9)$ & $323(319-328)$ & 4,151 & $2.5(2.5-2.6)$ & $470(468-472)$ \\
\hline Mono GN & 862 & $1.2(1.1-1.2)$ & $342(337-347)$ & 803 & $2.5(2.4-2.6)$ & $464(458-470)$ \\
\hline
\end{tabular}


TABLE 4.-Estimated age at $50 \%$ maturity $\left(A_{50} ;\right.$ years $)$ and length at $50 \%$ maturity $\left(L_{50} ; \mathrm{mm} ; 95 \%\right.$ confidence intervals in parentheses) for male and female walleyes $(N=$ number examined) collected by the Ohio Department of Natural Resources (ODNR), Ontario Ministry of Natural Resources (OMNR), and New York State Department of Environmental Conservation (NYSDEC) using monofilament gill-nets from the western basin (ODNR versus OMNR, September 1993-1995), central basin (ODNR versus OMNR, October 1989-2006), and eastern basin (OMNR versus NYSDEC, September 1989-2006) of Lake Erie.

\begin{tabular}{|c|c|c|c|c|c|c|}
\hline \multirow[b]{2}{*}{ Agency } & \multicolumn{3}{|c|}{ Male } & \multicolumn{3}{|c|}{ Female } \\
\hline & $N$ & $A_{50}$ & $L_{50}$ & $N$ & $A_{50}$ & $L_{50}$ \\
\hline \multicolumn{7}{|c|}{ Western basin } \\
\hline ODNR & 787 & $1.4(1.3-1.4)$ & $333(329-338)$ & 703 & $2.8(2.6-3.0)$ & $447(436-460)$ \\
\hline OMNR & 1,168 & $2.3(2.2-2.4)$ & $402(396-409)$ & 1,170 & $2.8(2.6-3.2)$ & $443(434-454)$ \\
\hline \multicolumn{7}{|c|}{ Central basin } \\
\hline ODNR & 958 & $1.2(1.1-1.2)$ & $344(339-349)$ & 904 & $2.5(2.4-2.6)$ & $463(457-469)$ \\
\hline OMNR & 4,265 & $0.9(0.9-1.0)$ & $324(320-328)$ & 3,553 & $2.3(2.3-2.3)$ & $454(451-456)$ \\
\hline \multicolumn{7}{|c|}{ Eastern basin } \\
\hline OMNR & 566 & $2.8(2.5-3.1)$ & $439(430-448)$ & 774 & $2.3(2.1-2.5)$ & $436(428-443)$ \\
\hline NYSDEC & 2,078 & $1.8(1.7-1.8)$ & $377(373-380)$ & 1,077 & $3.1(2.9-3.5)$ & $464(458-471)$ \\
\hline
\end{tabular}

between September and October (Figure 2a, b). Moreover, although some sex-age-specific $L_{50, a}$ estimates varied by gear (estimates for age- 1 males in the central basin) and agency (estimates for age- 1 males in the central basin and age- 2 males in the eastern basin), $L \mathrm{p}_{50, a}$ estimates were robust to gear; however, they might be sensitive to agency effects (Figure 2c-f).

\section{Among-Stock Variation in Maturation Indices}

Estimates of $A_{50}$ and $L_{50}$ for both male and female walleyes varied significantly among systems and assessment programs, but patterns were not necessarily consistent (Table 5). For example, whereas male $A_{50}$ estimates were relatively small for western basinODNR, central basin-ODNR, and central basinOMNR and relatively large for western basin-OMNR and eastern basin-OMNR, female $A_{50}$ estimates displayed dissimilar spatial patterns. Further, despite significant sensitivity of $A_{50}$ and $L_{50}$ with respect to agencies, indices for males tended to be greater in the eastern basin and Saginaw Bay than in the western and central basins. The spatial variation of female $A_{50}$ and $L_{50}$ was less pronounced and differed from the male pattern. Lastly, $L_{50}$ for both sexes was relatively small for Oneida Lake.

Sex-age-specific estimates of $L_{50, a}$ and $L \mathrm{p}_{50, a}$ also varied significantly among system-agency units. However, spatial patterns of $L_{50, a}$ and $L \mathrm{p}_{50, a}$ estimates were not consistent across ages. For example, although both maturation indices $\left(L_{50, a}\right.$ and $\left.L \mathrm{p}_{50, a}\right)$ for age-1 males were relatively large for Saginaw Bay and small for western basin-OMNR, the spatial pattern of these same indices for age-2 males was reversed (Figure 3A, B). Similarly, both indices for females showed inconsistent and somewhat ambiguous (perhaps confounded by sensitivity of the indices to agency effects) spatial patterns across ages; $L_{50, a}$ for age- 2 females from central basin-ODNR significantly varied from that of age-2 females from eastern basin-OMNR, but $L_{50, a}$ and $L \mathrm{p}_{50, a}$ for age- 3 females did not vary between the two system-agency units (Figure 3c, d). Further, although the $L_{50, a}$ and $L \mathrm{p}_{50, a}$ estimates for age- 1 males varied conspicuously between the western and central basins based on OMNR data, between-basin differences in these indices based on ODNR data were much smaller or not significant (Figure 3A, B). Despite such inconsistent patterns, two trends were particularly noticeable: (1) spatial variation in $L_{50, a}$ and $L \mathrm{p}_{50, a}$ estimates for males was more pronounced than that for females, and (2) although norms estimated for Lake Erie and Saginaw Bay tended to intersect, $L_{50, a}$ or $L \mathrm{p}_{50, a}$ estimates for Oneida Lake were relatively low and distinct from those of the other stocks (Figure 3a, c, d).

\section{Within-Stock Temporal Variation in Maturation Indices}

Temporal changes were evident for all of the maturation indices (our analysis was based on a coarse resolution, and we did not evaluate fine-scale interannual temporal changes). Although agency-related biases confounded the interpretation of among-stock variation in maturation indices, there is no indication that biases confounded interpretation of within-stock temporal patterns. Significant and variable temporal changes in $A_{50}$ and $L_{50}$ were detected for most stocks (Table 6). Although most male estimates tended to increase over time or remain unchanged, both indices decreased for central basin-OMNR males. On the other hand, female $A_{50}$ estimates tended to decrease or remain unchanged. Although all female $L_{50}$ estimates 

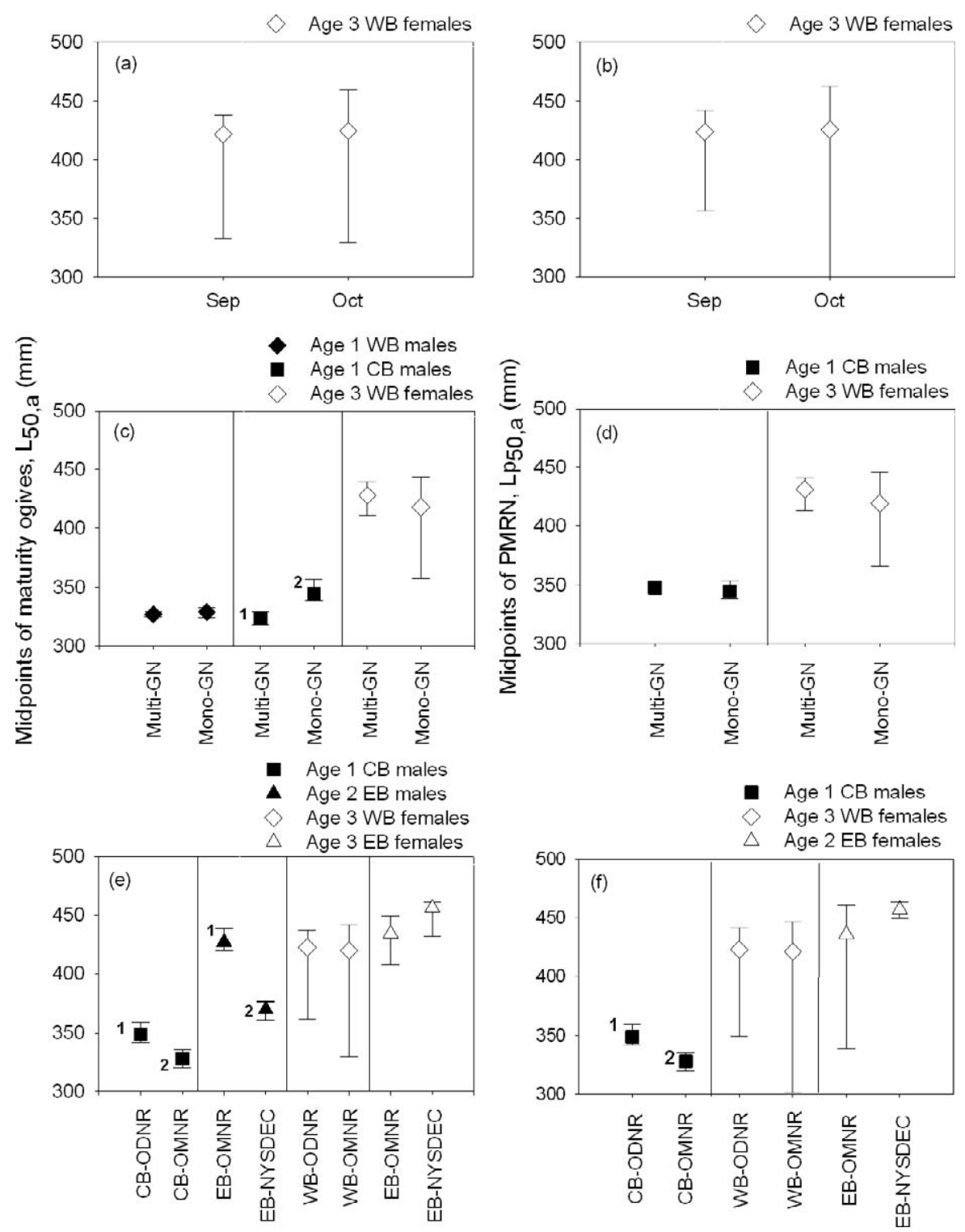

FIGURE 2.-Evaluation of the sensitivity of midpoints (with $95 \%$ confidence intervals) of Lake Erie walleye age-specific maturity ogives $\left(L_{50, a}\right.$; left panels) and probabilistic maturation reaction norms (PMRNs; $L \mathrm{p}_{50, a}$; right panels) to different assessment variables. The comparisons were based on age-specific and sex-specific subsets of data that generated estimable $L_{50, a}$ and $L \mathrm{p}_{50, a}$ (black symbols = males; white symbols = females; diamonds = Lake Erie western basin [WB]; squares $=$ central basin [CB]; triangles = eastern basin [EB]; other abbreviations are listed in Table 1). We evaluated month of sampling for (a) $L_{50, a}$ and (b) $L \mathrm{p}_{50, a}$, where September versus October comparisons were based on estimates for age- 3 WB females (ODNR monofilament gill-net data, 1992-1995); gear types for (c) $L_{50, a}$ and (d) $L \mathrm{p}_{50, a}$, where multifilament versus monofilament gill-net comparisons were based on estimates for age-1 WB males, age-1 CB males, and age-3 WB females (ODNR data, October 1992-2006); and agencies for (e) $L_{50, a}$ and (f) $L \mathrm{p}_{50, a}$, where ODNR versus OMNR comparisons were based on estimates for age-1 CB males and age-3 WB females and OMNR versus NYSDEC comparisons were based on estimates for age-2 EB males and age-3 EB females. Evaluation of agency effects was based on monofilament gill-net data from the WB (September 1993-1995), CB (October 1989-2006), and EB (September 1989-2006). Significantly different midpoints are indicated by different numbers. 
TABLE 5.-Estimated age at $50 \%$ maturity $\left(A_{50} ;\right.$ years $)$ and length at $50 \%$ maturity $\left(L_{50} ; \mathrm{mm} ; 95 \%\right.$ confidence intervals in parentheses) for male and female walleyes by lake system and agency (see Table 1 for abbreviations). All estimates were based on combined-gear (gear listed in Table 1) data collected during September and October of 1989-2006.

\begin{tabular}{lrccrccc}
\hline & \multicolumn{4}{c}{ Male } & & \multicolumn{3}{c}{ Female } \\
\cline { 2 - 3 } \cline { 7 - 8 } Lake-agency & \multicolumn{1}{c}{$N$} & $A_{50}$ & $L_{50}$ & & $N$ & $A_{50}$ & \multicolumn{1}{c}{$L_{50}$} \\
\hline WB-ODNR & 13,219 & $1.0(1.0-1.0)$ & $329(328-331)$ & & 7,739 & $2.5(2.5-2.5)$ & $459(458-461)$ \\
WB-OMNR & 4,254 & $2.2(2.1-2.3)$ & $395(392-398)$ & & 5,645 & $2.5(2.4-2.6)$ & $419(417-423)$ \\
CB-ODNR & 7,758 & $1.0(1.0-1.1)$ & $332(329-335)$ & & 6,792 & $2.5(2.5-2.5)$ & $465(463-466)$ \\
CB-OMNR & 5,072 & $1.0(1.0-1.0)$ & $328(324-331)$ & & 4,534 & $2.3(2.3-2.3)$ & $449(446-451)$ \\
EB-OMNR & 581 & $2.7(2.4-3.0)$ & $436(427-444)$ & & 828 & $2.3(2.1-2.5)$ & $434(426-441)$ \\
EB-NYSDEC & 2,078 & $1.8(1.7-1.8)$ & $377(373-380)$ & & 1,077 & $3.1(2.9-3.5)$ & $464(458-472)$ \\
Saginaw Bay & 2,747 & $1.7(1.6-1.7)$ & $383(379-386)$ & & 2,171 & $2.5(2.5-2.6)$ & $455(448-460)$ \\
Oneida Lake & 928 & $1.9(1.8-2.1)$ & $327(323-331)$ & 885 & $3.3(3.2-3.4)$ & $383(380-387)$ \\
\hline
\end{tabular}

changed significantly over time, the direction of change varied among system-agency units.

Some temporal changes in sex-age-specific $L_{50, a}$ and $L \mathrm{p}_{50, a}$ estimates were also evident, and increasing or decreasing trends were generally consistent between sexes and among age-classes (Figure 4). Age-specific
$L_{50, a}$ and $L \mathrm{p}_{50, a}$ estimates increased significantly for males and females in the western basin (based on both ODNR and OMNR data; Figure $4 \mathrm{a}-\mathrm{d}$ ). On the other hand, changes in $L_{50, a}$ and $L \mathrm{p}_{50, a}$ estimates for the central basin (based on ODNR data) and eastern basin (based on NYSDEC data) were not significant (Figure
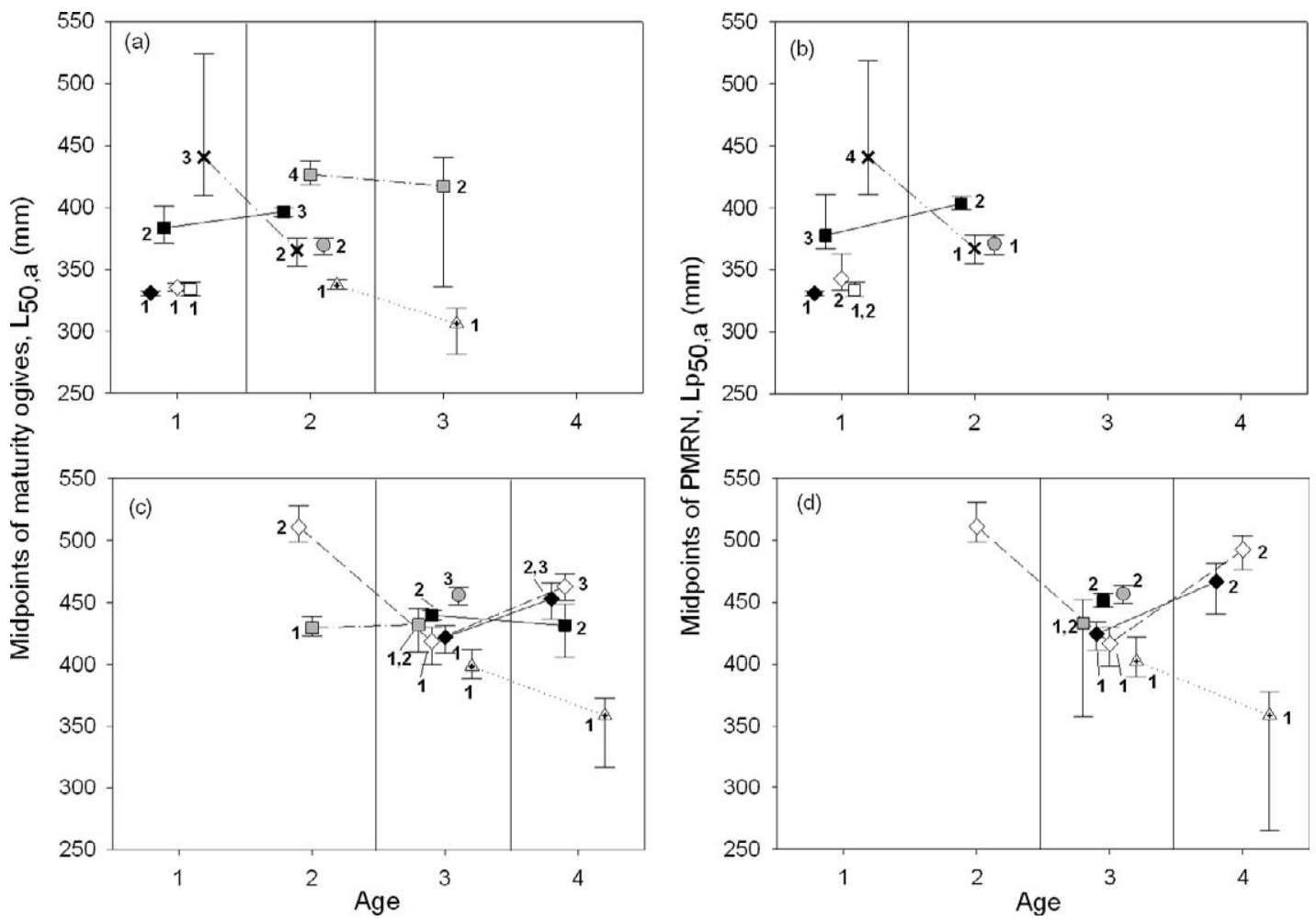

FIGURE 3.-Midpoints (with 95\% confidence intervals) of (a) age-specific maturity ogives $\left(L_{50, a}\right)$ and (b) probabilistic maturation reaction norms (PMRNs; $L \mathrm{p}_{50, a}$ ) for male walleyes; and (c) $L_{50, a}$ and (d) $\mathrm{Lp}_{50, a}$ for female walleyes collected from various systems by different agencies (abbreviations defined in Table 1; black diamonds = WB-ODNR, black squares $=$ WBOMNR, open diamonds $=\mathrm{CB}-\mathrm{ODNR}$, open squares $=\mathrm{CB}-\mathrm{OMNR}$, gray squares $=\mathrm{EB}-\mathrm{OMNR}$, gray circles $=\mathrm{EB}-\mathrm{NYSDEC}$, crosses $=$ Saginaw Bay, dotted triangles $=$ Oneida Lake. Significantly different midpoints are indicated by different numbers. To facilitate visual inspection, estimates for a given age are slightly offset along the $x$-axis. 
TABLE 6.-Estimated age at $50 \%$ maturity $\left(A_{50} ;\right.$ years $)$ and length at $50 \%$ maturity $\left(L_{50} ; \mathrm{mm} ; 95 \%\right.$ confidence interval in parentheses) for male and female walleyes in each lake-agency unit (see Table 1 for abbreviations) by cohort groupings. The temporal groups for each lake-agency unit were defined by dividing data into two approximately equal subsets based on estimated year-classes.

\begin{tabular}{|c|c|c|c|c|c|c|c|}
\hline \multirow[b]{2}{*}{ Lake-agency } & \multirow[b]{2}{*}{ Year-classes } & \multicolumn{3}{|c|}{ Male } & \multicolumn{3}{|c|}{ Female } \\
\hline & & $N$ & $A_{50}$ & $L_{50}$ & $N$ & $A_{50}$ & $L_{50}$ \\
\hline \multirow[t]{2}{*}{ WB-ODNR } & $<1990$ & 11,313 & $0.8(0.7-0.8)$ & $318(315-320)$ & 6,799 & $2.4(2.4-2.5)$ & $455(453-457)$ \\
\hline & $>1990$ & 8,716 & $1.0(1.0-1.1)$ & $328(326-330)$ & 5,878 & $2.5(2.5-2.5)$ & $461(459-463)$ \\
\hline \multirow[t]{2}{*}{ WB-OMNR } & $<1997$ & 2,798 & $1.9(1.9-2.0)$ & $379(376-383)$ & 2,765 & $2.5(2.4-2.6)$ & $427(422-431)$ \\
\hline & $>1997$ & 1,456 & $2.7(2.5-2.8)$ & $420(413-428)$ & 2,880 & $2.5(2.4-2.6)$ & $415(410-419)$ \\
\hline \multirow[t]{2}{*}{ CB-ODNR } & $<1990$ & 3,844 & $0.9(0.8-1.0)$ & $335(331-339)$ & 3,319 & $2.5(2.5-2.6)$ & $463(460-465)$ \\
\hline & $>1990$ & 5,214 & $1.1(1.0-1.1)$ & $329(327-332)$ & 4,645 & $2.5(2.5-2.6)$ & $469(467-471)$ \\
\hline \multirow[t]{2}{*}{ CB-OMNR } & $<1997$ & 2,005 & $1.3(1.2-1.3)$ & $349(345-353)$ & 2,230 & $2.3(2.2-2.3)$ & $440(435-444)$ \\
\hline & $>1997$ & 3,067 & $0.8(0.8-0.9)$ & $312(305-319)$ & 2,304 & $2.3(2.3-2.3)$ & $455(451-458)$ \\
\hline \multirow[t]{2}{*}{ EB-NYSDEC } & $<1993$ & 1,529 & $1.9(1.7-2.0)$ & $382(376-387)$ & 794 & $3.4(3.1-3.8)$ & $479(471-488)$ \\
\hline & $>1993$ & 1,397 & $1.8(1.7-1.8)$ & $375(371-379)$ & 890 & $2.8(2.7-2.9)$ & $460(453-466)$ \\
\hline \multirow{2}{*}{ Saginaw Bay } & $<1993$ & 1,522 & $1.5(1.4-1.5)$ & $384(379-389)$ & 1,035 & $3.0(2.9-3.1)$ & $496(491-502)$ \\
\hline & $>1993$ & 1,225 & $1.8(1.7-1.8)$ & $383(378-387)$ & 1,136 & $2.2(2.1-2.3)$ & $428(419-437)$ \\
\hline \multirow[t]{2}{*}{ Oneida Lake } & $<1985$ & 852 & $2.0(1.9-2.1)$ & $315(311-317)$ & 993 & $3.3(3.2-3.4)$ & $369(366-372)$ \\
\hline & $>1985$ & 880 & $1.9(1.8-2.1)$ & $327(323-331)$ & 885 & $3.3(3.2-3.4)$ & $383(381-386)$ \\
\hline
\end{tabular}

$4 \mathrm{e}, \mathrm{h})$. In addition, $L_{50, a}$ estimates for Oneida Lake age2 males increased over time, whereas other sex-agespecific $L_{50, a}$ and $L \mathrm{p}_{50, a}$ estimates for Oneida Lake did not change significantly over time (Figure 4I, J).

\section{Discussion}

By quantifying maturation schedules of walleye stocks via three types of maturation indices, we demonstrate that (1) $A_{50}$ and $L_{50}$ estimates are relatively sensitive to biases related to sampling procedures, including agency-related issues; (2) $L \mathrm{p}_{50, a}$ estimates are less sensitive to biases related to sampling time, gear, and agency, but $L_{50, a}$ estimates are influenced by gear and agency-specific samplingrelated biases; and (3) after accounting for age and length, walleye stocks appear to display intrinsically different maturation schedules (e.g., variation in $L \mathrm{p}_{50, a}$ ) among systems and over time. Standard assessments over time suggest that within-system temporal changes in PMRN midpoints are indicative of adaptive changes. Further, the congruency of life history expectations and the magnitude and consistency of across-system differences in PMRNs are suggestive of adaptive variation.

Although our evaluations of sensitivity of maturity indices were constrained within small changes in sampling time (September versus October) and similar gears (multifilament versus monofilament gill net), we showed that $A_{50}$ and $L_{50}$ estimates were sensitive to these changes and therefore would probably be sensitive to greater levels of changes in sampling procedures. Such great sensitivity to sampling biases suggests that it may be inappropriate to use these indices to quantify spatial and temporal variation in walleye maturation schedules when data collection involves various methods and assessment programs. Similarly, gear- and agency-related biases when estimating $L_{50, a}$ also may confound interpretation of maturation schedules. Further, although PMRNs are relatively robust to most sampling procedures examined, our evaluation is conservative and thus we do not suggest that PMRNs are unbiased. It is possible that PMRNs may be sensitive to more pronounced differences in sampling procedures.

After accounting for sampling time and gear, we found that maturation indices might be sensitive to agency-related differences in assessment methods. However, the mechanisms underlying agency differences are unclear. It is possible that by sampling in different areas within a basin of Lake Erie, agencies are collecting walleyes from different substocks. However, the eastern and western basins are fairly small, so walleyes readily move throughout these areas (Wang et al. 2007). Alternatively, such agency-related biases may result from uncertainty in identifying maturation state of walleyes during fall. Mature walleyes in Lake Erie start developing gonads during August to October (Henderson et al. 1996), and it is possible that some walleyes that will spawn in the spring may be evaluated as immature during September surveys. Although misidentification of maturation state for walleyes could be reduced by using spring survey data, lack of immature fish in spring samples would preclude this analysis. We believe that although misidentification of maturation state may be relatively pronounced for walleyes, such misidentification may be minor for surveys that more closely precede spawning time. 

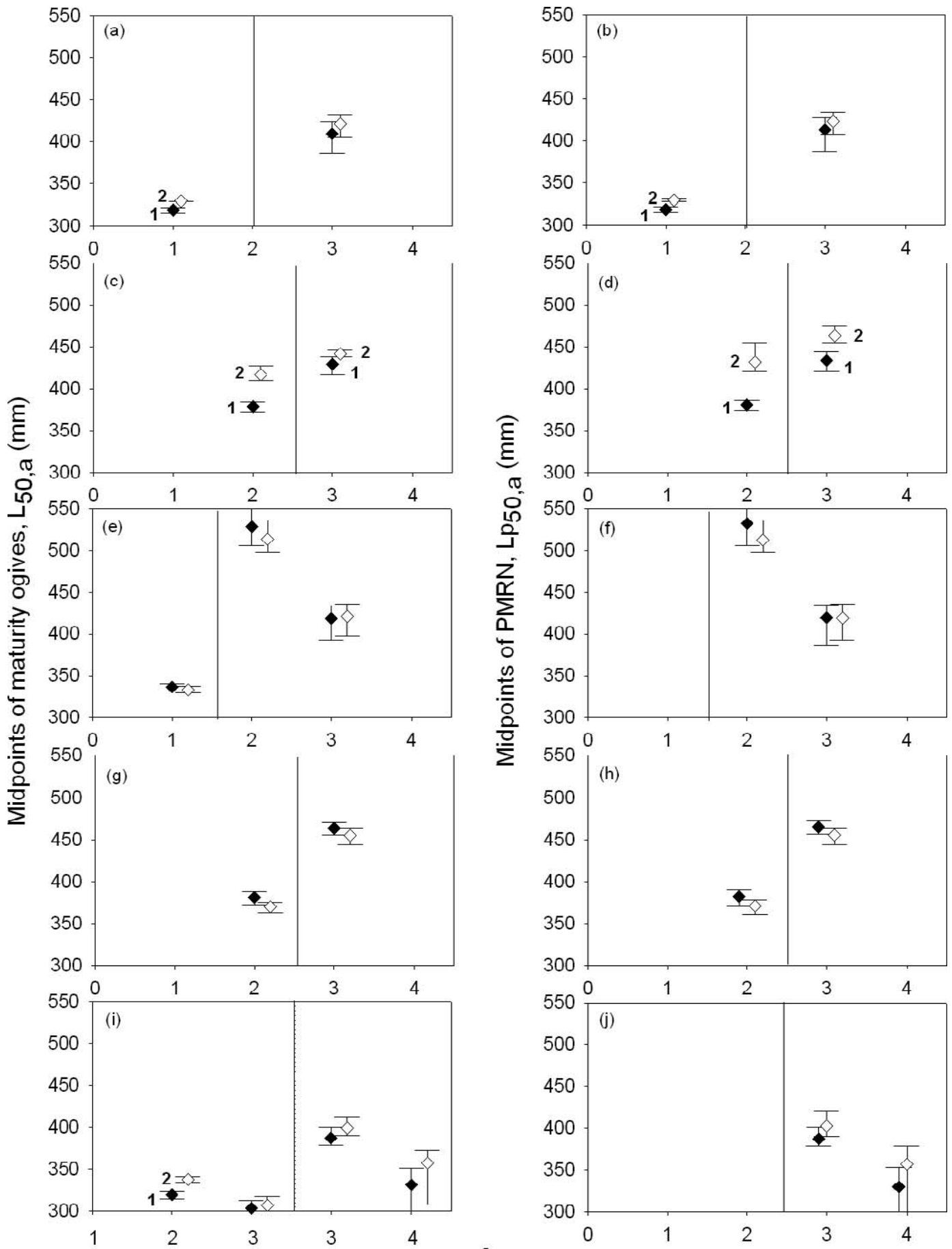

Age

FIGURE 4.-Temporal trends of midpoints (with $95 \%$ confidence intervals) of age-specific maturity ogives $\left(L_{50, a}\right.$; left panels) and probabilistic maturation reaction norms (PMRNs; $L \mathrm{p}_{50}$; right panels) for walleyes collected from various lake-agency units (abbreviations in Table 1): (a) $L_{50, a}$ and (b) $L \mathrm{p}_{50, a}$ for WB-ODNR; (c) $L_{50, a}$ and (d) $L \mathrm{p}_{50, a}$ for WB-OMNR; (e) $L_{50, a}$ and (f) $L \mathrm{p}_{50, a}$ for CB-ODNR; (g) $L_{50, a}$ and (h) $L \mathrm{p}_{50, a}$ for EB-NYSDEC; and (i) $L_{50, a}$ and (j) $L \mathrm{p}_{50, a}$ for Oneida Lake. Temporal groups per lake-agency unit were defined by dividing data into two approximately equal subsets based on estimated year-classes (i.e., individuals born before or after cutoff year indicated for division in Table 6; black diamonds $=$ pre-cutoff year-classes, open diamonds = post-cutoff year-classes. Age-specific estimates to the left of vertical dotted lines are for males; those to the right are for females. Significantly different midpoints are indicated by different numbers. 
Uncertainty in identifying walleye maturation state and sex of young fish during fall could have strong impact on maturation indices. For example, although females generally mature at older ages and larger lengths than males (Henderson and Morgan 2002), early to mid-fall OMNR data for the eastern and western basins indicate that the $A_{50}$ and $L_{50}$ estimates for males were inflated and that female $L_{50}$ was relatively small. This may reflect a differential ability to evaluate maturity status of the two sexes, or it may reflect other sexual differences (e.g., survival). Regardless, such uncertainty in data quality also may have confounded within-agency, across-basin variation in PMRN estimates. We found that PMRN estimates varied conspicuously between the western and central basins based on OMNR data but not ODNR data. Given that monthly distributions of ODNR samples were approximately equal in both basins but varied across basins for OMNR data, it is possible that between-basin variation in PMRNs based on OMNR data were inflated due to difference in time of sampling. Although we could have avoided this bias by only using October data, the combination of samples from September and October was in many cases necessary to achieve a sufficient sample size for PMRN analysis (Barot et al. 2004a, 2004b).

By accounting for the effects of growth and mortality rates, spatial and temporal variation in midpoints of PMRNs may identify adaptive responses among walleye stocks and over time. Furthermore, comparison between PMRNs and $A_{50}$ and $L_{50}$ indices may inform the role of plasticity in maturation schedules (e.g., significant variation in $A_{50}$ and $L_{50}$ but not $\left.L \mathrm{p}_{50, a}\right)$. Thus, these maturation indices are complementary. Moreover, although spatial and temporal trends of $L_{50, a}$ and $L \mathrm{p}_{50, a}$ are similar, values of these estimates can be different because of estimation procedures. While PMRNs are relatively invariable to changes in growth and mortality, maturity ogives can be influenced by changes in growth and mortality (Dieckmann and Heino 2007). Consequently, maturity ogive estimates should not be used as an alternative for PMRN estimates.

Potential biases related to agency-specific assessment methods preclude robust interpretation of across-agency spatial variation in PMRN estimates. However, there is no evidence of within-system biases for PMRNs, and we believe it is appropriate to consider within-system, within-agency temporal variation of our results. Although $A_{50}$ and $L_{50}$ for females in eastern basinNYSDEC decreased over time, nonsignificant changes in the $L \mathrm{p}_{50, a}$ for age-3 females suggest that such temporal changes may be a plastic response (e.g., $A_{50}$ and $L_{50}$ were sensitive to temporal changes in length at age, but PMRNs were not). Moreover, although growth rates did not change (ODW 2006), $L_{50, a}$ and $L \mathrm{p}_{50, a}$ for western basin fish showed significant signs of temporal increases, suggesting that fish matured at larger lengths for a given age in recent year-classes. Such temporal trends in walleye maturation schedules differ from those of many commercial fishes (e.g., several commercially harvested stocks of Atlantic cod Gadus morhua were observed to express decreases in midpoints of PMRNs over time: Olsen et al. 2004, 2005). Although several authors suggest that intensive (e.g., commercial) size-selective harvest may induce evolutionary changes that lead to early maturation and decreased growth patterns (e.g., Stokes et al. 1993; Conover and Munch 2002; Law 2007), it is possible that realized changes in maturation and growth patterns for exploited populations may or may not correspond to the direction of genetic selection. For example, Swain et al. (2007) suggest that increased selectivity for large fish by fisheries from the 1980s to early 1990s may have induced genetic selection towards shorter lengths for age-4 Atlantic cod, but instead estimated changes in age-4 lengths showed increasing trends. Also, the selection experienced by walleyes in Lake Erie may not be comparable with that for some other commercially harvested species, and the shifts in midpoints of PMRNs may reflect evolutionary responses to other sources of selection (e.g., changes in abiotic conditions). Alternatively, management of Lake Erie walleyes may have influenced observed temporal PMRN patterns. Harvest of walleyes in Lake Erie has involved defining quotas for whole-lake annual catches based on long-term monitoring of spawning and recruitment status (GLFC 2008). Such proactive adjustments of harvest intensity may have contributed to an increase in midpoints of PMRNs for western basin walleyes.

Spatially, across-agency variation of walleye maturation schedules must be considered with the caveat that such variation may be due to intrinsic variation among stocks, agency-related assessment biases, or both. Nonetheless, variation in maturation schedules (inferred from estimated PMRNs and growth trajectories), mortality, and growth patterns for these walleye stocks appear to correspond to the expectations based on life history theory: (1) populations experiencing high mortality are expected to show an adaptive response of the PMRNs towards early maturation and (2) fast juvenile growth rates should, either through phenotypic plasticity or adaptive response, favor early maturation (Hutchings 1993). Walleyes in Oneida Lake experience relatively slow juvenile growth (mean total length at age $1=170 \mathrm{~mm}$; He et al. 2005) and low mortality rates. Estimated midpoints of PMRNs are relatively small for walleyes in this system, suggesting 
that the fish mature at relatively small sizes, even at older ages. Conversely, before 2004, walleyes in Saginaw Bay expressed relatively fast juvenile growth rates (e.g., mean total length at age 1 was $350 \mathrm{~mm}$ versus $300 \mathrm{~mm}$ in the western basin of Lake Erie and $330 \mathrm{~mm}$ in the eastern and central basins; Fielder et al. 2000; Fielder and Thomas 2006; OMNR data, present study). Consistent with these growth patterns, estimated midpoints of PMRNs suggest that males in Saginaw Bay mature at relatively early ages (e.g., age 2) and large sizes. Interestingly, patterns of PMRN estimates for walleyes across Lake Erie basins do not correspond to the divergent life history patterns of the stocks. Eastern basin walleyes grow relatively fast and experience low mortality rates compared with western basin walleyes (Wang 2003; A. Cook, unpublished data). However, the age-specific PMRN estimates for males were smaller in the eastern basin, suggesting that they mature earlier; estimates for females did not vary significantly among basins. Such intricate relationships between estimated maturation schedules and other life history traits of Lake Erie walleyes suggest that (1) these stocks may have experienced complex local selection pressures, (2) adaptive variation in maturation schedules of these stocks is not fully characterized by PMRN estimates (see below), or (3) agency-related assessment biases obscure the depiction of intrinsic maturation schedules (including uncertainty in identifying maturity state during fall surveys).

In addition to assessment-related biases, other factors may also confound interpretation of lengthbased PMRN patterns. For example, stocks may potentially mix among interconnected systems. Although we used fall survey data to ensure inclusion of both juvenile and adult fish, among-basin or betweenlake movements of walleyes imply that some fish collected in the three Lake Erie basins and Saginaw Bay were not residents of these systems. However, tag-recapture studies suggest that during fall, most fish occupy their natal system (Fielder and Thomas 2006; Wang et al. 2007). Further, although estimation of PMRNs involves controlling for length and age, several authors suggest that because length and age do not fully account for plastic variation, it may be inappropriate to interpret variation in PMRN estimates as indicative of genetically distinct maturation schedules (Kraak 2007; Marshall and McAdam 2007). Recent studies show that weight or condition may serve as additional explanatory variables for estimating PMRNs (Grift et al. 2007; Wright 2007). Indeed, condition could have an important effect on maturation processes of walleyes (Henderson and Nepszy 1994; Henderson et al. 1996; Henderson and Morgan 2002). At the individual level, onset of maturation of female walleyes begins during early fall when visceral fat is replenished, and gonadal development during fall and winter depends on the amount of available visceral fat (Henderson et al. 1996). As a result, PMRN estimates might better represent adaptive variation in maturation schedules by incorporating information on weight or condition. However, because (1) length and weight are often correlated and (2) adding more explanatory variables may introduce additional assumptions and measurement error (as suggested by Dieckmann and Heino 2007), we believe that the spatial or temporal variation in length-based PMRN estimates would probably be consistent with the weight-based estimates (as shown by Grift et al. 2007; Wang et al. 2008).

In conclusion, age and length at maturation may reflect variation in reproductive potential and may have direct implications for management of walleyes. Furthermore, it is important to monitor and understand the role of adaptive versus plastic effects on maturation traits because changes from the adaptive effects may be more difficult to reverse (Conover et al. 2009; Stenseth and Dunlop 2009). Based on our results, we suggest that interpreting variation in maturation schedules based solely on $A_{50}$ and $L_{50}$ would be inappropriate because these indices are unsuitable for informing adaptive changes and because they are sensitive to sampling methods and biases. We recommend using multiple maturation indices, such as $A_{50}, L_{50}$, and PMRN estimates. Although estimating PMRNs requires a relatively large sample size, multiple indices collectively help to reveal both adaptive and plastic variation. As estimated for a number of marine stocks (e.g., North Sea plaice Pleuronectes platessa and Atlantic cod) described by long-term data sets, PMRNs can be widely estimated for fishes in the Great Lakes, where there are several agency programs that routinely collect biological data (e.g., Wang et al. 2008). It is, however, critical to recognize that agency effects can bias these maturation indices, and future research efforts are needed to reconcile sampling protocols among agencies and reduce uncertainty in identifying maturation state (e.g., conducting surveys close to spawning season). Thus, in large systems where stock assessment and fisheries management involve different agencies, we recommend that agencies consider adopting similar survey methods when possible and conducting experimental surveys to evaluate agencyinduced and sampling-induced biases related to estimation of age and maturation state.

\section{Acknowledgments}

This study was funded by the U.S. Fish and Wildlife Service through the Great Lakes Restoration Act 
program and was supported by the National Oceanic and Atmospheric Administration (NOAA) Great Lakes Environmental Research Laboratory (GLERL). This is NOAA-GLERL contribution 1517 and CU Biological Field Station contribution 268.

\section{References}

Barot, S., M. Heino, L. O’Brien, and U. Dieckmann. 2004a. Estimating reaction norms for age and size at maturation when age at first reproduction is unknown. Evolutionary Ecology Research 6:659-678.

Barot, S., M. Heino, L. O’Brien, and U. Dieckmann. 2004b. Long-term trend in the maturation reaction norm of two cod stocks. Ecological Applications 14:1257-1271.

Billington, N., R. J. Barrette, and P. D. N. Hebert. 1992. Management implications of mitochondrial DNA variation in walleye stocks. North American Journal of Fisheries Management 12:276-284.

Billington, N., and P. D. N. Hebert. 1988. Mitochondrial DNA variation in Great Lakes walleye (Stizostedion vitreum) populations. Canadian Journal of Fisheries and Aquatic Sciences 45:643-654.

Colby, P. J., and S. J. Nepszy. 1981. Variation among stocks of walleye (Stizostedion vitreum vitreum): management implications. Canadian Journal of Fisheries and Aquatic Sciences 38:1814-1831.

Conover, D. O., and S. B. Munch. 2002. Sustaining fisheries yields over evolutionary time scales. Science 297:94-96.

Conover, D. O., S. B. Munch, and S. A. Arnott. 2009. Reversal of evolutionary downsizing caused by selective harvest of large fish. Proceedings of the Royal Society B 276:2015-2020.

Dieckmann, U., and M. Heino. 2007. Probabilistic maturation reaction norms: their history, strengths, and limitations. Marine Ecology Progress Series 335:253-269.

Dunlop, E. S., B. J. Shuter, and M. S. Ridgway. 2005. Isolating the influence of growth rate on maturation patterns in the smallmouth bass (Micropterus dolomieu). Canadian Journal of Fisheries and Aquatic Sciences 62:844-853.

Einhouse, D. W., J. L. Markham, D. L. Zeller, R. C. Zimar, B. J. Beckwith, and M. A. Wilkinson. 2005. 2004 Annual report to the Lake Erie Committee. New York State Department of Environmental Conservation, Albany.

Fielder, D. G. 2002. Sources of walleye recruitment in Saginaw Bay, Lake Huron. North American Journal of Fisheries Management 22:1032-1040.

Fielder, D. G., J. E. Johnson, J. R. Weber, M. V. Thomas, and R. C. Haas. 2000. Fish population survey of Saginaw Bay, Lake Huron, 1989-1997. Michigan Department of Natural Resources, Fisheries Research Report 2052, Ann Arbor.

Fielder, D. G., and M. V. Thomas. 2006. Fish population dynamics of Saginaw Bay, Lake Huron 1998-2004. Michigan Department of Natural Resources, Fisheries Research Report 2083, Ann Arbor.

Forney, J. L. 1965. Factors affecting growth and maturity in a walleye population. New York Fish and Game Journal 12:217-232.

Forney, J. L. 1977. Evidence of inter- and intraspecific competition as factors regulating walleye (Stizostedion vitreum vitreum) biomass in Oneida Lake, New York. Journal of the Fisheries Research Board of Canada 34:1812-1820.

GLFC (Great Lakes Fishery Commission). 2008. Catch limits recommended for Lake Erie walleye and yellow perch for 2008. Available: www.glfc.org/pressrel/pr080318.pdf (May 2008).

Goede, R. W., and B. A. Barton. 1990. Organismic indices and an autopsy-based assessment as indicators of health and condition of fish. Pages 93-108 in S. Marshall Adams, editor. Biological Indicators of Stress in Fish. American Fisheries Society, Symposium 8, Bethesda, Maryland.

Grift, R. E., M. Heino, A. D. Rijnsdorp, S. B. M. Kraak, and U. Dieckmann. 2007. Three-dimensional maturation reaction norms for North Sea plaice. Marine Ecology Progress Series 334:213-224.

Grift, R. E., A. D. Rijnsdorp, S. Barot, M. Heino, and U. Dieckmann. 2003. Fisheries-induced trends in reaction norms for maturation in North Sea plaice. Marine Ecology Progress Series 257:247-257.

He, J. X., L. G. Rudstam, J. L. Forney, A. J. VanDeValk, and D. J. Stewart. 2005. Long-term patterns in growth of Oneida Lake walleye: a multivariate and stage-explicit approach for applying the von Bertalanffy growth function. Journal of Fish Biology 66:1459-1470.

Heino, M., U. Dieckmann, and O. R. Godø. 2002. Measuring probabilistic reaction norms for age and size at maturation. Evolution 56:669-678.

Henderson, B. A., and G. E. Morgan. 2002. Maturation of walleye by age, size and surplus energy. Journal of Fish Biology 61:999-1011.

Henderson, B. A., and S. J. Nepszy. 1994. Reproductive tactics of walleye (Stizostedion vitreum) in Lake Erie. Canadian Journal of Fisheries and Aquatic Sciences 51:986-997.

Henderson, B. A., J. L. Wong, and S. J. Nepszy. 1996. Reproduction of walleye in Lake Erie: allocation of energy. Canadian Journal of Fisheries and Aquatic Sciences 53:127-133.

Hutchings, J. A. 1993. Adaptive life history effected by agespecific survival and growth rate. Ecology 74:673-684.

Kershner, M. W., D. M. Schael, R. L. Knight, R. A. Stein, and E. A. Marschall. 1999. Modeling sources of variation for growth and predatory demand of Lake Erie walleye (Stizostedion vitreum) 1986-1995. Canadian Journal of Fisheries and Aquatic Sciences 56:527-538.

Kitchell, J. F., D. J. Stewart, and D. Weininger. 1977. Applications of a bioenergetics model to yellow perch (Perca flavescens) and walleye (Stizostedion vitreum vitreum). Journal of the Fisheries Research Board of Canada 34:1922-1935.

Knight, R. L. 1997. Successful interagency rehabilitation of Lake Erie walleye. Fisheries 22:16-17.

Kraak, S. B. M. 2007. Does the probabilistic maturation reaction norm approach disentangle phenotypic plasticity from genetic change? Marine Ecology Progress Series 335:295-300.

Law, R. 2000. Fishing, selection, and phenotypic evolution. ICES Journal of Marine Science 57:659-668.

Law, R. 2007. Fisheries-induced evolution: present status and 
future directions. Marine Ecology Progress Series 335:271-277.

Marshall, C. T., and B. J. McAdam. 2007. Integrated perspectives on genetic and environmental effects on maturation can reduce potential for errors of inference. Marine Ecology Progress Series 335:301-310.

McDermid, J. L., P. E. Ihssen, W. N. Sloan, and B. J. Shuter. 2007. Genetic and environmental influences on life history traits in lake trout. Transactions of the American Fisheries Society 138:1018-1029.

McParland, T. L., M. M. Ferguson, and A. P. Liskauskas. 1999. Genetic population structure and mixed-stock analysis of walleyes in the Lake Erie-Lake Huron corridor using allozyme and mitochondrial DNA markers. Transactions of the American Fisheries Society 128:1055-1067.

Merker, R. J., and R. C. Woodruff. 1996. Molecular evidence for divergent breeding groups of walleye (Stizostedion vitreum) in tributaries to western Lake Erie. Journal of Great Lakes Research 22:280-288.

ODW (Ohio Division of Wildlife). 2006. Ohio's Lake Erie fisheries 2005. Annual status report. Federal Aid in Fish Restoration Project F-69-P. Ohio Department of Natural Resources, Division of Wildlife, Fairport.

Olsen, E. M., M. Heino, G. R. Lilly, M. J. Morgan, J. Brattey, B. Ernande, and U. Dieckmann. 2004. Maturation trends indicative of rapid evolution preceded the collapse of northern cod. Nature (London) 428:932-935.

Olsen, E. M., G. R. Lilly, M. Heino, M. J. Morgan, J. Brattey, and U. Dieckmann. 2005. Assessing changes in age and size at maturation in collapsing populations of Atlantic cod (Gadus morhua). Canadian Journal of Fisheries and Aquatic Sciences 62:811-823.

Rudstam, L. G., A. J. VanDeValk, C. M. Adams, J. T. H. Coleman, J. L. Forney, and M. E. Richmond. 2004. Cormorant predation and the population dynamics of walleye and yellow perch in Oneida Lake. Ecological Applications 14:149-163.

Schneider, J. C. 2001. Aging scales of walleye, yellow perch, and northern pike. Michigan Department of Natural Resources, Fisheries Technical Report 2001-1, Ann Arbor.

Schneider, J. C., and J. H. Leach. 1977. Walleye (Stizostedion vitreum vitreum) fluctuations in the great lakes and possible causes, 1800-1975. Journal of the Fisheries Research Board of Canada 34:1878-1889.
Stearns, S. C. 1992. The evolution of life histories. Oxford University Press, Oxford, UK.

Stenseth, N. C., and E. S. Dunlop. 2009. Evolution: unnatural selection. Nature (London) 457:803-804.

Stokes, T. K., J. M. McGlade, and R. Law, editors. 1993. The exploitation of evolving resources. Lecture Notes in Biomathematics Number 99. Spangler-Verlag, Berlin.

Strange, R. M., and C. A. Stepien. 2007. Genetic divergence and connectivity among river and reef spawning groups of walleye (Sander vitreus vitreus) in Lake Erie. Canadian Journal of Fisheries and Aquatic Sciences 64:437-448.

Swain, D. P., A. F. Sinclair, and J. M. Hanson. 2007. Evolutionary response to size-selective mortality in an exploited fish population. Proceedings of the Royal Society B 274:1015-1022.

Taylor, W. W., M. A. Smale, and R. W. Brown. 1992. An evaluation of size versus age dependent maturation of lake whitefish stocks in the upper Great Lakes. Polish Archives of Hydrobiology 39:269-277.

Trippel, E. A. 1995. Age at maturity as a stress indicator in fisheries. BioScience 45:759-771.

VanDeValk, A. J., C. M. Adams, L. G. Rudstam, J. L. Forney, T. E. Brooking, M. A. Gerken, B. P. Young, and J. T. Hooper. 2002. Comparison of angler and cormorant harvest of walleye and yellow perch in Oneida Lake, New York. Transactions of the American Fisheries Society 131:27-39.

Wang, H.-Y. 2003. Spatial analysis of movement, life history, and habitat quality of walleye (Stizostedion vitreum) in Lake Erie. Master's thesis. University of Michigan, Ann Arbor.

Wang, H.-Y., T. O. Höök, M. P. Ebener, L. C. Mohr, and P. J. Schneeberger. 2008. Spatial and temporal variation of maturation schedules of lake whitefish (Coregonus clupeaformis) in the Great Lakes. Canadian Journal of Fisheries and Aquatic Sciences 65:2157-2169.

Wang, H.-Y., E. S. Rutherford, H. A. Cook, D. W. Einhouse, R. C. Haas, T. B. Johnson, R. Kenyon, B. Locke, and M. W. Turner. 2007. Movement of walleyes in Lakes Erie and St. Clair inferred from tag return and fisheries data. Transactions of the American Fisheries Society 136:539-551.

Wright, P. J. 2007. Understanding the maturation process for field investigations of fisheries-induced evolution. Marine Ecology Progress Series 335:279-283. 